\title{
EDITOR'S REPORT
}

$M$ ental health professionals facing what appear to be raging rivers of human maldevelopment, inadequacy, and despair do not often see themselves as the little Dutch boy with the magical thumb. With the passage of two pieces of legislation, the body politic has urged that this magical appendage begin to cope with leaks in the Grand Coulee and Hoover Dams. The two pieces of legislation are the amendments to the Social Security Act (Title XIX) 1967, setting out the Early Periodic Screening Diagnosis and Treatment Program (EPSDT), and the more recently enacted P.L. 94-63, Title II, Section 204, providing grants for Community Mental Health Centers to plan and develop consultation and educational services as a separately administered program.

With notable exceptions, the opportunity afforded to communities by these legisla-

\section{Notice to Readers}

Beginning with the current Volume, this Journal will discontinue publication of its special March issue, devoted to 500-word digests of papers presented at the Annual Meeting of the American Orthopsychiatric Association.

Neither format nor content of the four regular Journal issues will be in any way affected by discontinuance of the Digest issue. As in the past, some of the papers presented at the Annual Meeting will be selected for publication in full in the Joumal. Similarly, brief abstracts of Annual Meeting papers will continue to be printed in the Program of the Association's Annual MeetIng. tive sanctions has been met by total zeros. In California, the EPSDT program, available only to Medicare-Medicaid families, was broadened to include all children and adolescents. The program has managed some small beginnings in the prevention of infectious disease, genetically determined problems, and sensory and dental difficulties. However, everyone runs and hides when developmental and mental health issues arise. As far as consultation and educational services go, they go not far. It may be too early for some CMHCs to contemplate such possibilities since it's only been more than ten years since they've been $\mathrm{C} \&$ Eing.

Our ass dragging in these preventive areas stems more from metaphorical constructions on possible actions than from our unwillingness to act. Somehow we can't see our way to helping children grow without tagging them as hyperactive, pre-schizophrenic, brain damaged, delinquent, or, horror of horrors, dyslexic. We have so long worked in psychopathology that the notion of positive growth, positively conceived and implemented, completely mystifies us. Suppose one were to see screening in EPSDT not as a process of separating out high risk children (for what?), but one of providing key services for children screened as possible utilizers of growthsupporting services. In the case of P.L. $94-63$, I can recall only rare instances where this Journal has received solid research or conceptual papers on how C\&E scrvices might be significant and useful in prevention.

For some mystical reason I believe, with W. Shakespeare, that "A little fire is quickly trodden out, which being suffered rivers cannot quench." How about trodding out a few?-Eli M. Bower, Ed.D. 